A CORRELATION FOR BOILING HEAT TRANSFER TO SATURATED FLUIDS IN CONVECTIVE FLOW

John C. Chen

MASTER

Brookhaven National Laboratory

Upton, New York

December 26, 1962

Facsimile Price $\$ 3,60$

Microfilm Price $\$$

Available from the

Office of Technical Services

Department of Commerce

Washington 25, D. C.

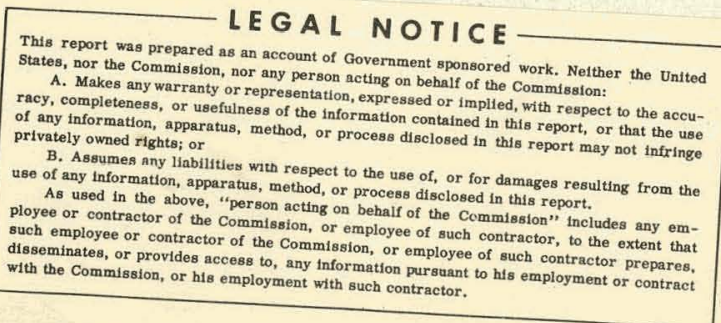

This work was done under the auspices of the U. S. Atomic Energy Commission

This paper was submitted for publication in the open literature at least 6 months prior to the issuance date of this Micro card. Since the U.S.A.E.C. has no evidence that it has been published, the paper is being distributed in Microcard form as a preprint. 


\section{DISCLAIMER}

This report was prepared as an account of work sponsored by an agency of the United States Government. Neither the United States Government nor any agency Thereof, nor any of their employees, makes any warranty, express or implied, or assumes any legal liability or responsibility for the accuracy, completeness, or usefulness of any information, apparatus, product, or process disclosed, or represents that its use would not infringe privately owned rights. Reference herein to any specific commercial product, process, or service by trade name, trademark, manufacturer, or otherwise does not necessarily constitute or imply its endorsement, recommendation, or favoring by the United States Government or any agency thereof. The views and opinions of authors expressed herein do not necessarily state or reflect those of the United States Government or any agency thereof. 


\section{DISCLAIMER}

Portions of this document may be illegible in electronic image products. Images are produced from the best available original document. 


\title{
A CORRELATION FOR BOILING HEAT TRANSFER \\ TO SATURATED FLUIDS IN CONVECTIVE FLOW \\ John C. Chen
}

\begin{abstract}
An additive mechanism of micro- and macro-convective heat transfer was formulated to represent boiling heat transfer with net vapor generation to saturated; non-metallic fluids in convective. flow. The final equations are:

$$
\begin{aligned}
& h_{\text {mic }}=0.00122 \frac{k_{I}^{0.79} c_{D L}^{0.45} \rho_{L}^{0.49} \Delta T^{0.24} \Delta P^{0.75} g_{C}^{0.25}}{\sigma^{0.5} \mu_{I}^{0.29} \lambda^{0.24} \rho_{V}^{0.24}} \times s \\
& h_{\operatorname{mac}}=0.023 \frac{\operatorname{Pr}_{I}^{0.4} \operatorname{Re}_{L}^{0.8} k_{I}}{D} \times F \\
& h=h_{\text {mic }}+h_{\text {mac }}
\end{aligned}
$$

The second equation will be recognized as the Dittus-Boelter equation with the additional factor $F$. The two functions $F$. and $s$ are defined as

$$
\begin{aligned}
& F=\left(R e / R e_{I}\right)^{0.8} \\
& S=\left(\Delta T_{e} / \Delta t\right)^{0.99}
\end{aligned}
$$

where $\mathrm{Re}$ is the effective Reynolds number for the two-phase fluid and $\Delta \mathrm{T}_{\mathrm{e}}$ is the effective superheat for bubble growth. F and $s$ were obtained as functions of the Martinelli parameter and the two-phase Reynolds number, respectively.

The correlation was tested with available data: for water and organic fluids. Data from different sources which could not be satisfactorily correlated by existing correlations were shown to be quite well correlated by the one presently proposed. The average deviation between calculated and measured boiling coefficients for all data points from nine experimental cases was $\pm_{11 \%}$.

Brookhaven National Laboratory, Upton, N. Y.

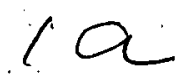




\section{Introduction}

It has become almost a tradition that any paper dealing with the subject of boiling heat transfer should start by recognizing the complexity of the phenomenon. This complexity is especially evident in the case of convective boiling with net generation of vapor. Under these condition, the heat transfer is effected by the various flow parameters and the vapor quality as well as by the parameters which are pertinent in pool boiling. Figure la illustrates the wide range of local conditions and different flow regimes which could exist along the length of a boiler for such a case. Figure Ib illustrates typical fluid and wall temperature profiles corresponding to these various flow regimes. In the subcooled region, both the fluid and the wall temperatures increase as the liquid gains sensible heat. At the point where nucleate boiling starts, the wall temperature begins to decrease. The fluid temperature continues to increase until it reaches its saturation value, from which point on, it decreases gradually corresponding to the decreasing pressure. As the fluid progresses into the annular flow regime with continuously increasing vapor qualities, it is seen that the wall temperature decreases, reflecting an increasing heat transfer coefficient. This condition often exists into the fog-flow region. Finally, liguid deficiency occurs and there is a sudden decrease in the heat transfer coefficient with a corresponding rise in the wall temperature.

In view of the widely different conditions that could exist at various points along a boiler, it is this author's opinion that it would be entirely unprofitable either to measure over-all "average" coefficients or to attempt to correlate them. The only hope of obtaining results which can be 
generalized is to work with local heat transfer coefficients. Furthermore, since the mechanisms of heat transfer may be different for the various flow regimes, it seems that any analytical study or correlation could be expected to apply strictly to only one of the possible flow regimes. It is therefore necessary that the region of applicability be clearly defined for a particular analytical study or correlation. The region of interest in this study is defined by the following conditions:

1... saturated, two-phase fluid in convective flow

2. vertical, axial flow

3. stable flow

4. no slug flow

5. no liquid deficiency

6. heat flux less than critical flux

These conditions usually occur with annular flow or annularmist flow in the quality range of approximately 1 to $70 \%$.

Background

There have been a number of experimental studies in this field reporting data on systems with water, organic fluids and even liquid metals. In this present analysis, we are concerned only with the first two classes of fluids. In some of these studies, the authors presented equations correlating their own data. In almost all such cases, it was implied that the correlations could be generalized to apply to other systems.

One of the first major works in this area was that of Dengler and Addoms [1] who in 1952 obtained local boiling coefficients for water in upward vertical flow through a oneinch tube. They proposed the following empirical correlation for their data.

[1] Numbers in parenthesis refer to numbered references in Bibliography. 


$$
h=3.5 \frac{F_{D A}}{\left(x_{t t}\right)^{0.5}} \times h_{L}^{\prime}
$$

where $h_{I}$ is evaluated by the conventional Dittus-Boelter equation.

$$
\left.h_{I}^{\prime}=0.023 \frac{k_{L}}{D}\left(\frac{D G}{\mu_{I}}\right) 0.8 \frac{C_{P I} \mu_{L}}{k_{I}}\right) 0.4
$$

In the above correlation, $F_{D A}$ represents the correction factor to be applied for points where nucleate boiling exists.

In 1956, Guerrieri and Talty [2] reported local boiling coefficients for a number of organic liquids in single-tube vertical boilers. They were able to correlate $88 \%$ of their data to within $\pm_{20 \%}$ by the following equations.

$$
\begin{aligned}
& h=0.187\left(\frac{r^{*}}{\delta}\right)^{-5 / 9} \times 3.4 \frac{h_{L}}{\left(x_{t t}\right)^{0.45}} \\
& h_{I}=(1-x)^{0.8 h_{I}} \\
& r^{*}=\frac{2 R T_{S}^{2} \sigma}{P_{s} \lambda\left(T_{W}{ }^{-T} T_{s}\right)} \\
& \delta=\frac{1 O_{\mu_{L}}}{\rho_{L}}\left[\frac{4 \rho_{L}}{(\mathrm{dP} / \partial L) g_{C}}\right]^{1 / 2}
\end{aligned}
$$

In 1959, Bennett and co-workers [3] reported data for water flowing vertically in annular test sections. They compared their data with both the correlation of Dengler and Addoms and that of Guerrieri and Talty but, in each case, found considerable scatter. They then proposed their own correlation where 
the local heat flux, $g / A$, was used as a multiplicative correction factor.

$$
h=0.64 \frac{1}{\left(x_{t t}\right)^{0.74}} \times h_{I} \times\left(\frac{g}{A}\right)^{0.11}
$$

In 1960, sani [4] presented data for water in vertical flow through a tube. The author compared his results with the available correlations but found the deviations to be quite substantial. No new correlation was proposed.

In 1962, schrock and Grossman [5] published a report on force-convective boiling of water in tubes. They introduced the boiling number, $B_{0}$, as an extra variable and obtained a correlation of the form,

$$
\begin{aligned}
& h=7,400\left[B_{0}+1.5 \times 10^{-4}\left(\frac{1}{x_{t t}}\right)^{2 / 3}\right] h_{L}^{\prime} \\
& B_{0}=\left(\frac{g}{A}\right)\left(\frac{1}{G \lambda}\right)
\end{aligned}
$$

The authors reported that this equation correlated their data to within $\pm 35 \%$. However, when sani [4] compared his results with this correlation, he discovered that the experimentally measured coefficients were almost twice as great as those predicted.

There are a number of other correlations reported in the Iiterature. Most of them, however, deal with either sub-cooled boiling or boiling with horizontal flow and therefore are irrelevant to the present study.

\section{Comparison of Existing Correlations}

From a leterature survey as summarized above, there appeared to be a need for testing the various correlations against a representative body of available data. This was carried out 
with the aid of a digital computer and some of the results are shown in Figures 2, 3, 4, and 5. In these figures the predicted values of the boiling coefficients have been plotted against the experimental values, the $45^{\circ}$ line representing perfect correlation. Due to lack of space, only a representative fraction of the 564 data points used in this check have been shown in these figures. The range of experimental conditions covered by the data in this comparison are summarized in Table I. Figure 2 shows that while the correlation of Dengler and Addoms [1] represents the authors' own data fairly well, it predicts coefficients which are too high when compared with data from other sources. Figure 3 shows that the equation proposed by Guerrieri and Talty[2] correlates their own results quite well but predicts coefficients much lower than those measured by Dengler and Addoms and by Sani. This correlation, however, appears to predict coefficients of the right order of magnitude when compared with the data of schrock and Grossman. Figure 4 shows that Bennett's [3] correlation appears to predict reasonable values for the majority of the water data although the scatter is guite great. However, the predicted coefficients are approximately 50\% too low when compared with the organic data. In general, the correlation of Schrock and Grossman [5], as shown in Figure 5, appears to be better than the other three. With respect to the organic data, this correlation gives values which are approximately $30 \%$ too low. The correlation does appear to bisect the water data although the scatter ranges from $a+30 \%$ to $-50 \%$.

In general, it appears that none of the correlations is entirely satisfactory for general use. Indications are that the pertinent variables have not been correctly accounted for in these correlations. 
Derivation of Equations

It is postulated that there are two basic mechanisms which take part in the heat transfer process for the boiling of saturated fluids with flow. These are (I) the ordinary macroconvective mechanism of heat transfer which normally operates with flowing fluids, and (2) the micro-convective mechanism associated with bubble-nucleation and growth. It is further postulated that these two mechanisms are additive in their contributions to total heat transfer. The concept of additive contributions is not new. Rohsenow [6] in 1952 first suggested that the heat transfer associated with convection and with boiling can be added. Gambill [7] recently applied the additive concept to correlate boiling burnout data. In both of these cases, sub-cooled nucleate boiling was treated, and the authors found that the convective and the boiling contributions could be super-imposed without modifications. In this present study, we are interested in saturated boiling with net vapor generation, and it is felt that for this case the two mechanisms would not have their normal effects but would be modified by effects of quality and by the interaction of one mechanism on the other. Under this general premise, equations describing these two mechanisms were formulated as follows.

Considering first the macro-convective mechanism, it was recognized tidet at the two limits of $0 \%$ and $100 \%$ quality, the macro-convective heat transfer should be described by the DittusBoelter type of correlation. It was then postulated that in the two-phase region where there are both liquid and vapor present, the macro-convective heat transfer should still be described by a modified form of the Dittus-Boelter equation.

$$
h_{\operatorname{mac}}=0.023(\operatorname{Re})^{0.8}(\mathrm{Pr})^{0.4} \frac{\mathrm{k}}{\mathrm{D}}
$$


In this equation, the Prandtl and the Reynolds numbers and the thermal conductivity represent effective values associated with the two-phase fluid. We may define three parameters as ratios of these quantities divided by the liquid quantities.

$$
\begin{aligned}
& \beta=\operatorname{Pr} / \mathrm{Pr}_{I} \\
& \gamma=k / k_{I} \\
& F=\left(\operatorname{Re} / R e_{L}\right)^{0.8}=\left(\operatorname{Re} \times \frac{\mu_{L}}{D G z}\right)^{0.8}
\end{aligned}
$$

In the case of ordinary fluids, i.e., not liquid metals, the Prandtl numbers of the liquid and of the vapor are normally of the same magnitude. The Prandt number of the two-phase fluid should therefore also be of the same magnitude. Furthermore, since the heat is transferred through an annular film of liquid adhering to the wall, it is expected that the Iiquid properties would have the dominant effect. For these reasons it is reasonable to assume that. $\beta$ and $\gamma$ may be taken to be unity as a first approximation. Eq. (5) may then be re-written as

$$
h_{\text {mac }}=0.023\left(R e_{L}\right)^{0.8}\left(\operatorname{Pr}_{I}\right)^{0.4} \frac{k_{L}}{D} F
$$

The only unknown function in Eq. (9) is $F$, the ratio of the two-phase Reynolds number to the liquid Reynolds number, based on the liquid fraction of the flow. This ratio is strictly a flow parameter; and therefore by analogy to momentum transfer in two-phase flow, it may be assumed that $F$ is a function of the Martinelii parameter $\mathrm{x}_{t t}$. This postulate has hean verified and the actual dependence of $F$ on $x_{t t}$ obtained by comparison with experimental data.

The analysis of Forster and zuber [8] was taken as a basis for the formulation of a micro-convective mechanism of heat 
transfer. The Forster and zuber analysis was derived for the case of pool boiling and resulted in the following equation for the boiling Nusselt number.

$$
\begin{aligned}
& N u_{b}=0.0015\left(R_{b}\right)^{0.62}\left(\operatorname{Pr}_{L}\right)^{0.33}=\frac{h_{b} r_{b}}{k_{L}} \\
& r_{b}=\frac{\Delta T}{\lambda \rho_{V}} \cdot\left(\frac{2 \pi k_{L} \rho_{L} C_{P L}^{\sigma}}{\Delta P}\right)^{0.5}\left(\frac{\rho_{L}}{g_{C} \Delta \mathrm{P}}\right)^{0.25} \\
& \operatorname{Re}_{b}=\frac{\pi k_{L} C_{P L}}{\mu_{L}}\left(\frac{\rho_{L} \Delta T}{\rho_{V} \lambda}\right)^{2}
\end{aligned}
$$

These equations are based on the premise that the Reynolds number for. micro-convective boiling heat transfer is governed by the growth rate of bubbles. This rate is described by the Rayleigh equation which Forster and zuber solved to show that the product of the bubble radius and the bubble growth rate is a constant for a specific superheat.

$$
r_{b} \frac{d r_{b}}{d \dot{\theta}}=\frac{\pi k_{L} \rho_{L} C_{p I}}{\left(\lambda \rho_{V}\right)^{2}}(\Delta T)^{2}
$$

As illustrated in Fig. 6 for the case of boiling from a superheated wall, whether in pool boiling or convective boiling, the degree of superheat ailudily is not constant across the boundary layer. Due to this fact, the Reynolds number used in the Forster-zuber equation actually is an effective Reynolds number representative of some mean, effective superheat. The difference bctween this effective superheat and the wall superheat is small for the case of pool boiling and was neglected in Forster and Zuber's derivation. However, this difference cannot be neglècted in the case of convective boiling since the temperature gradient is now dependent on flow rate 
and vapor guality and would generally be much steeper than in the corresponding pool boiling case with the same wall superheat.

In using Forster and Zuber's formulation to represent micro-convective heat transfer in convective boiling, this effect was taken into account by writing Eq. (10) in terms of effective $\Delta T$ and $\Delta \mathrm{p}$.

$$
h_{\text {mic }}=0.00122 \frac{k_{I}^{0.79} C_{C_{L}}^{0.45} \rho_{I}{ }^{0.49} g_{C}^{0.25}}{\sigma^{0.5}{ }_{\mu_{I}}^{0.29} \lambda^{0.24} \rho_{\rho_{V}}^{0.24}}\left(\Delta \mathrm{T}_{e}\right)^{0.24}\left(\Delta \mathrm{P}_{e}\right)^{0.75}
$$

Then a suppression factor, $S$, was defined as the ratio of the effective superheat to the total superheat of the wall

$$
S=\left(\frac{\Delta T_{e}}{\pi T}\right) 0.99
$$

The ratio is arbitrarily taken to the 0.99 power in order that $S$ would appear to the first power in the final equations.

By the Clausius and Clapeyron equation,

$$
\begin{aligned}
& \left(\Delta T_{e}\right)^{0.99}=\left(\frac{T_{e}}{\lambda p_{v}^{j}}\right)_{T_{e}}^{0.75}\left(\Delta T_{e}\right)^{0.24}(\Delta P)^{0.75} \\
& (\Delta T)^{0.99}=\left(\frac{T}{\lambda p_{v}{ }^{j}}\right)_{T}^{0.75} \cdot(\Delta T)^{0.24}(\Delta P)^{0.75}
\end{aligned}
$$

For $\frac{\Delta T}{T} \ll 1$, we can write,

$$
\left(\frac{T_{e}}{\lambda \rho_{V}^{j}}\right)_{T_{e}} \cong\left(\frac{r_{T}}{\lambda \rho_{V} j}\right)_{T}
$$

and,

$$
S=\left(\frac{\Delta \mathrm{T}_{e}}{\Delta \mathrm{T}^{\prime}}\right)^{0.24}\left(\frac{\Delta \mathrm{P}_{\epsilon}}{\Delta \mathrm{P}}\right)^{0.75}
$$


Combining with Iq. (12), we then obtain an expression for the micro-convective coefficient in terms of the suppression factor and the total superheat.

$$
h_{\text {mic }}=0.00122 \frac{k_{I}^{0.79} C_{P I}^{0.45} \rho_{I}^{0.49} g_{C}^{0.25}}{\sigma .5 \mu_{I}^{0.29} 0.24 \sigma_{\rho_{V}}^{0.24}}(\Delta T)^{0.24}(\Delta P)^{0.75} \mathrm{~S}
$$

The suppression factor, $s$, approaches unity at zero flow rate and zero at infinite flow rate. It was postulated, subject to experimental verification, that in all ranges of flow $s$ can be represented as a function of the local two-phase Reynolds number.

The total heat transfer coefficient is then obtained as the sum

$$
h=h_{\text {mic }}+h_{\operatorname{mac}}
$$

The two unknowns in the above equations are the Reynolds number factor, $F$, and the suppression factor, $S$. These two functions were determined empirically from experimental data by the following procedure.

A Iirst estimate of $F$ was obtained by plotting the ratio of experimental two-phase heat transfer coefficient divided by the liquid coefficient as a function of the reciprocal Martinelli parameter. Using this estimate of $F$, values of $h_{\text {mic }}$ were obtained from Eq. (17) and (18) by subtracting the estimated values of $h_{\text {mac }}$ from the experimental data. The results were then pitted against two-phase Reynolds number and a bestfit curve was obtained for $s$. Using this first estimate of the $S$ function, a second estimate of $F$ was calculated from the experimental data and compared with the original estimate of F. This iterative procedure was repeated for a total of ten trials, at the end of which, the two functions were found to remain relatively constant from one trial to the next and were 
assumed to have converged. In this procedure, only data from experiments with substantial macro-convective heat transfer were used to correlate the F function, and only data from experiments with substantial micro-convective heat transfer were used to correlate the $S$ function. This selective weighting of the data served to increase precision in the determination of the two functions. The results are shown in Figs. 7 and 8. The shaded areas on these two plots represent the scatter of the data around the two correlating functions. It is seen that $\mathrm{F}$ increases with increasing values of the reciprocal Martinelli parameter, indicating that the effective turbulence associated with two-phase flow increases with increasing vapor fraction. The suppression factor, $S y$ is seen to approach unity at low values of the two-phase Reynolds number and decrease. asymptotically to zero at high values of the two-phase Reynolds number. These results are ceasonable in indicating that at low flow rates and low fraction vapor the boiling mechanism plays a relatively important part, whereas at high flow rates and high fraction vapor, the boiling is suppressed and the macro-convective heat transfer mechanism becomes increasingly important.

The final correlation is given by Egs. (9), (17), and (18) with the two correlating functions, $F$ and $S$, represented graphically in Figs. 7 and 8.

Comparison with experimental data

This correlation was tested against available data for both water and organic fluids. The comparisons are shown in Figs. 9 and 10. It is seen that this correlation fits the data from all, rather than from just one or two, of the sources. It also reduces the scatter quite substantially. The points presented in Fig. 9 include data for water, methanol, cyclonexane, 
and pentane. The mechanism and resulting equations postulated above appear to correlate all these data guite well. The average deviation for Dengler and Addoms' water' data was 14.7\%; for Schrock and Grossman's water data, 15.1\%; for Guerrieri and Talty's methanol data, 11.3\%; for their cyclohexane data, $13.6 \%$, and for their pentane data, $11.9 \%$. It is interesting to note that one of the sets best correlated by this formulation is the data of sani for water in downflow through a tube. The deviation for this set of data is only $8.5 \%$. This indicates that for the range of flow conditions encountered, the direction of vertical flow makes no appreciable difference. Previously, there was some uncertainty on this question since Schrock and Grossman had not been able to demonstrate consistency between their upflow results and sani's downflow results.

Figure 10 shows further comparisons of this correlation. with experimental results. Results for benzene and heptane are presented here along with resuits for water taken by Bennett et al. It is interesting to note that Bennett's data can also be correlated by this formulation in view of the fact that his coefficients were obtained on annuli whereas the other data were all obtained on round tubes. The equivalent diameter used to correlate Bennett's annular data was four times the cross sectional area divided by the heated perimeter. The average deviations for Bennett's water data and for the benzene and heptane data of Guerrieri and Talty are $10.8 \%$, 6.3\%, and $11.0 \%$ respectively.

Another method of testing this correlation is to see if it can predict correctly the wall temperature profile along the length of a boiler when all other conditions are given. some results from such.tests are shown in Fig. 11. Part (a) 
shows a comparison with data from one of schrock and Grossman's runs in which the incoming liquid was sub-cooled. It is seen that for the initial lengths of the boiler, the measured wall temperatures diverge from the calculated values. However, for later lengths of the boiler where vapor quality becomes greater than $2 \%$ and annular flow could exist, the calculated wall temperatures are seen to be verified by the experimental measurements. Part. (b) of the same figure shows results of a comparison with data from one of sani's runs. In this case, the fluid entered with $7 \%$ vapor quality, and annular flow likely existed through the entire length of the boiler. It is seen that the calculated and measured wall temperatures are in good agreement.

It is also of interest to see if this correlation can correctly predict the variation of the ratio $\mathrm{h} / \mathrm{h}_{\mathrm{I}}$ with Martinelli parameter $x_{t t}$. The majority of data available in the literature are presented as plots of $\mathrm{h} / \mathrm{h}_{\mathrm{L}}$ vs. $1 / \mathrm{x}_{\mathrm{tt}}$. Many investigators [2], [3], [5] have found that at high values of $1 / x_{t t}$, the data converge to a single line; whereas at low values of $1 / \mathrm{x}_{t t}$, the data seem to diverge in parameter curves. This divergence has not been satisfactorily reproduced by any of the previous theoretical equations. Fig. 12 shows curves of $\mathrm{h} / \mathrm{h} \mathrm{L}$ calculated by this correlation. It is seen that these calculated curves do show the characteristic divergence at low.values of $1 / x_{t t}$ and, in fact, when compared with experimental data for identical conditions (Curve 2), excellent agreement is obtained. Furthermore, the above analysis indicates that at high values of $\mathrm{I} / \mathrm{x}_{\text {t.t }}$. the ratio $\mathrm{h} / \mathrm{h}_{\mathrm{I}}$ should converge to the ratio $\left(\operatorname{Re} / R_{L}\right)^{0.8}$, i.e., the $F$ function.

Tabie I lists the range of experimental conditions covered by the data which were used in the various comparisons above. Table II summarizes the average deviations for this 
and for the other correlations when tested against these data. It is seen that the combined average deviation for this correlation is $\pm 11 \%$, approximately one-third the deviations for the other correlations. Thus it appears that for the range of conditions listed in Table $I$, this correlation markedly improves the chances of accurately predicting two-phase boiling coefficients.

\section{Summary}

The case of boiling heat transfer to saturated, ordinary fluids in convective flow was treated in this study with the hope of developing a method for predicting the heat transfer coefficients. For the regime of annular or annular mist-flow, it was postulated that the total heat transfer is comprised of contributions from micro-convective and macro-convective mechanisms. The micro-convective contribution to heat trans: fer was then derived from the Forster and zuber correlation for pool boiling heat transfer. A Dittus-Boelter type of equation was formulated to account for the macro-convective contribution. In these formulations, two, dimensionless functions, $S$ and $F$, were proposed to account for the suppression of nucleate boiling by the forced convective flow and for the increase in turbulence due to two-phase flow. These two correlating functions were determined empirically from available data and are presented graphically.

Using this correlation, it was shown that the wall temperature profile along a boiler and the curves of $h / h_{I}$ vs. $1 / \mathrm{x}_{t t}$ can be predicted correctly. In testing this correlation against all pertinent data from nine experimental cases reported in the literature for both water and organic fluids, the average deviation was found to be $\pm 11 \%$. This is a substantial improvement over existing correlations. 
This correlation is recommended for use in predicting boiling heat transfer coefficients for saturated, non-metallic fluids in convective flow. While the same type of mechanism is expected to apply also to boiling liquid metals, the specific correlation presented here would not be applicable without modification. For water and organics it is expected to be applicable in the quality range of approximately 1 to $70 \%$ vapor. Acknowledgements

The author wishes to express his appreciation to Dr. O. E. Dwyer for his constructive discussions during the course of this investigation and to Mr. Michell J. Small for his invaluable assistance in carrying out the necessary calculations. 


\section{BIBLIOGRAPHY}

[1] C. E. Dengler and J. N. Addoms, "Heat Transfer Mechanism for Vaporization of Water in a Vertical tube," Chemical Engineering Progress Symposium Series, 52, No. 18, 1956, pp. $95-103$.

[2] S. A. Guerrieri and R. D. Talty, "A Study of Heat Transfer to organic Liquids in Single-tube, Natural-circulation, Vertical-tube Boilers," Chemical Engineering Progress Symposium Series, $\underline{52}$, No. 18, 1956, pp. 69-77.

[3] J. A. R. Bennett, J. G. Collin, H. R. C. Pratt, and J. D. Thornton, "Heat Transfer to Two-Phase Gasuliquid Systems," AERE Report AERE-R3159, 1959.

[4] R. L. Sani, "Downflow Boiling and Non-boiling Heat Transfer in a Uniformly Heated tube," UCRI Report, UCRI 9023 , 1960.

[5] V. E. Schrock and L. M. Grossman, "Forced Convection Boiling in Tubes," Nuclear Science and Engineering, 12, 1962, pp. 474-481.

[6] W. M. Rohsenow, "Heat Transfer, A Symposium," 1952 , Engineering Research Institute, University of Michigan, Ann Arbor, Michigan.

[7] W. R. Gambill, "Generalized Prediction of Burnout Heat Flux for Flowing, Sub-cooled, Wetting Liquids," A.I.Ch.E. Preprint 17, Fifth National Heat Transfer Conference, Houston, 1962.

[8] H. K. Forster and N. Zuber, "Dynamics of Vapor Bubbles and Boiling Heat Transfer," A.I.Ch.E. Journal, I, No. 4, 1955, pp. 531-535. 
TABLE I

Range of Conditions for Data Used in Testing Correlation

\begin{tabular}{|c|c|c|c|c|c|c|c|}
\hline Reference & Fluid & Geometry & Flow & $\begin{array}{c}\text { Pressure } \\
\text { (psia) }\end{array}$ & $\begin{array}{c}\text { Flow Vel. } \\
\left(\mathrm{ft} / \mathrm{sec} l i \dot{q}_{.}\right)\end{array}$ & $\begin{array}{l}\text { Quality } \\
\text { (wt. \%) }\end{array}$ & $\begin{array}{c}\mathrm{Q} / \mathrm{A} \times 10^{-4} \\
(\mathrm{Btu}) /(\mathrm{hr})\left(\mathrm{Et} \mathrm{t}^{2}\right)\end{array}$ \\
\hline 1 & water & turie & up & $8-40$ & $0.2-4.8$ & $15-71$ & $2.8-20$ \\
\hline 5 & water & tube & up & $42-505$ & $0.8-14.7$ & $3-50$ & $6.5-76$ \\
\hline 4 & water & tuke & down & $16-31$ & $0.8-2.7$ & $2-14$ & $1.4-5.0$ \\
\hline 3 & water & anriulus & up & $15-35$ & $0.2-0.9$ & $1-59$ & $3.2-16$ \\
\hline 2 & methanol & tube & up & 15 & $1.0-2.5$ & $1-4$ & $0.7-1.7$ \\
\hline 2 & cyclohexane & tube & up & 15 & $1.3-2.8$ & $2-10$ & $0.3-1.3$ \\
\hline 2 & pentane & tube & up & 15 & $0.9-2.2$ & $2-12$ & $0.3-1.2$ \\
\hline 2 & heptane & tube & up & 15 & $1.0-2.4$ & $2-10$ & $0.2-0.9$ \\
\hline 2 & benzene & tube & up & 15 & $1.0-2.4$ & $2-9$ & $0.4-1.3$ \\
\hline
\end{tabular}

J. C. Chen 
TABLE II

Comparjson of Correlations

\section{Data}

Dengler \& Addoms (water)

Schrock \& Grossman (water)

Sani (water)

Bennett et al. (water)

Guerrieri \& Talty (methanol)

Guerrieri \& Talty (cyclohexane)

Guerrieri \& Talty (benzene)

Guerrieri \& Talty (heptane)

Guerrieri \& Talty (pentane)

combined average for all data
Average Percent Deviations for Correlations

\begin{tabular}{lcccc}
$\begin{array}{l}\text { Average Percent } \\
\text { Dengler } \\
\text { \& Addoms }\end{array}$ & $\begin{array}{c}\text { Guerrieri } \\
\text { \& Talty }\end{array}$ & $\begin{array}{c}\text { Bennett } \\
\text { et al. }\end{array}$ & $\begin{array}{c}\text { Schrock } \\
\text { \& Grossman }\end{array}$ & $\begin{array}{c}\text { This } \\
\text { Correlation }\end{array}$ \\
\hline 30.5 & 62.3 & 20.0 & 20.3 & 14.7 \\
89.5 & 16.4 & 24.9 & 20.0 & 15.1 \\
26.9 & 70.3 & 26.5 & 48.6 & 8.5 \\
17.9 & 61.8 & 11.9 & 14.6 & 10.8 \\
42.5 & 9.5 & 64.8 & 62.5 & 11.3 \\
39.8 & 11.1 & 65.9 & 50.7 & 13.6 \\
65.1 & 8.6 & 56.4 & 40.1 & 6.3 \\
61.2 & 12.3 & 58.0 & 31.8 & 11.0 \\
66.6 & 9.4 & 59.2 & 35.8 & 11.9 \\
38.1 & 42.6 & 32.6 & 31.7 & 11.0
\end{tabular}

J. C. Chen 


\section{Nomenclature}

$\mathrm{B}_{0}$

$c_{p}$

D

$\mathrm{dP} / \mathrm{dL}$

F

$\mathrm{F}_{\mathrm{DA}}$

G

$g_{c}$

h

$h \dot{I}$

$h_{L}$

j

k

Nup

$\mathrm{P}$

$\operatorname{Pr}$

$\mathrm{g} / \mathrm{A}$

$r_{b}$

Re

$\operatorname{Re}_{\mathrm{b}}$

$\mathrm{Re}_{\text {I }}$

$S$

T temperature, $\left({ }^{\circ} \mathrm{R}\right)$

$x$

$x_{\text {t七 }}$

$z$

diameter, (Ft)

pressure (psf)

Prandt 1 number

weight fraction vapor

boiling number; $\frac{\sigma / A}{\lambda G}$

heat capacity, (Btu)/(Ib) $\left({ }^{\circ} \mathrm{F}\right)$

pressure drop along boiler, (psf)/(Ft)

Reynolds number factor, $\left(R e / R e_{L}\right) 0.8$

Dengler and Addoms' correction factor, see Eq.

mass flow velocity, (Lb)/(Hr) $\left(F t^{2}\right)$

gravitational constant

two-phase heat transfer coefficient, (Btu)/( $\mathrm{Hr})\left(\mathrm{Ft}^{2}\right)\left({ }^{\circ} \mathrm{F}\right)$

total Iiquid heat transfer coefficient, see Eq.

fraction liquid heat transfer coefficient, see Eq.

Joule's constant, 778 (Ft) (Lib)/(Btu)

thermal conductivity, $(\mathrm{Btu}) /(\mathrm{Hr})(\mathrm{Ft})\left({ }^{\circ} \mathrm{F}\right)$

Nusselt number for bubble, see Eq. (10)

heat flux, (Btu) ( $\mathrm{Hr})\left(F \mathrm{t}^{2}\right)$

radius of bubble, see $\mathrm{Eq}$. (10)

effective Reynolds number for two-phase Fluid.

Reynolds number for bubble

Reynolds number for liquid fraction

suppression factor, $\left(\Delta T_{e} / \Delta T\right) 0.99$

Martinelli parameter, $\left(\frac{z}{x}\right)^{0.9}\left(\frac{\rho_{v}}{\rho_{I}}\right) 0.5{ }_{\left(\frac{\mu}{\mu_{V}}\right)}^{\mu_{V}} 0.1$.

weight fraction liquid 
$\beta$

$\operatorname{Pr} / P_{I}$

Y

$k / k_{\text {I }}$

$\Delta \mathrm{P}$

difference in vapor pressure corresponding to $\Delta T$, (PSf)

$\Delta \mathrm{T}$

superheat, $T_{W}-T_{S}$

$\Delta \mathbf{T}_{e}$

effective superheat with flow, see Eq.

$\lambda$ latent heat of vaporization, $(B t u) /(I b)$

$\mu$ viscosity, $(\mathrm{I}, \mathrm{b}) /(\mathrm{Ft})(\mathrm{Hr})$

$\rho$ density, $(\mathrm{Ib}) /\left(\mathrm{Ft}^{3}\right)$

$\sigma \quad \cdots$ vapor-liquid. surface tension, $(I B) /(F t)$

subscripts :

none value for two-phase fluia

e effective value with flow

I value for liquid

$s$ value at saturation conaition

$v$ value for vapor

w value at wall condition 


\section{Captions for Illustrations}

Figure 1 Conditions Along Boiler

(a) Flow Regimes

(b) Longitudinal Temperature Profiles

Figure 2 Comparison of Correlation of Dengler and Addoms with Experimental Results from Various Sources

Figure 3 Comparison of correlation of Guerrieri and Talty with Experimental Results from Various sources

Figure 4 Comparison of Correlation of Bennett et al. with

Experimental Results from Various sources

Figure 5 Comparison of Corrèlation of schrock and Grossman with r. Experimental Results from Various sources

Figure 6 Temperature Profiles for Pool Boiling and for Convective Boiling with the same Total superheat

Figure 7 Reynolds Number Factor, F

Figure 8 . Suppression Factor, $S$

Figure 9 Comparison of this correlation with Experimental Results from Various sources

Figure 10 Further Comparison of this Correlation with Experimental Results from Various sources

Figure 11 Comparison of Calculated and Measured Wall Temperatures (a) Data of Schrock and Grossmain (b) Data of Sani

Figure 12 calculated and Measured Ratios of $\mathrm{h} / \mathrm{h}_{\mathrm{L}}$ as Functions of the Martinelii parameter 


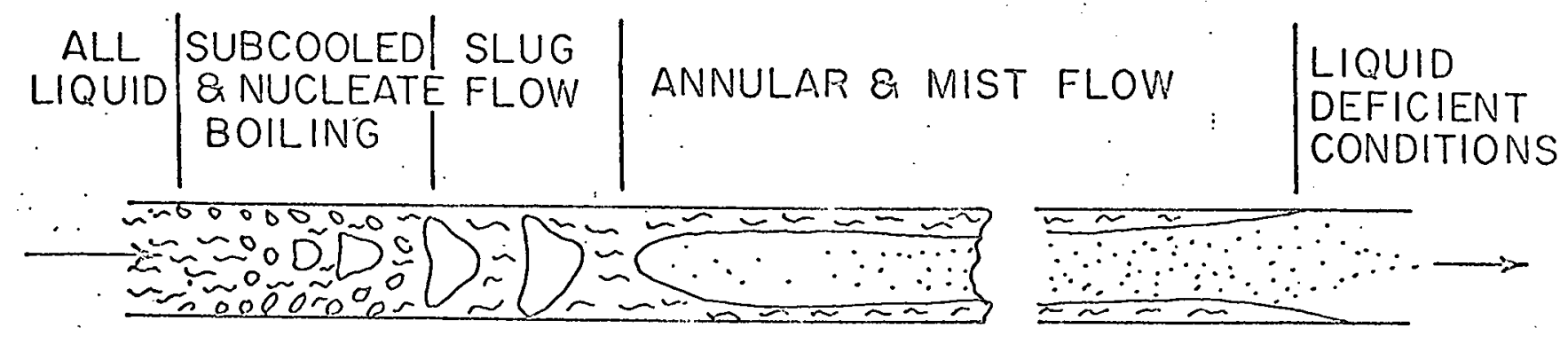

(A) FLOW REGIMES

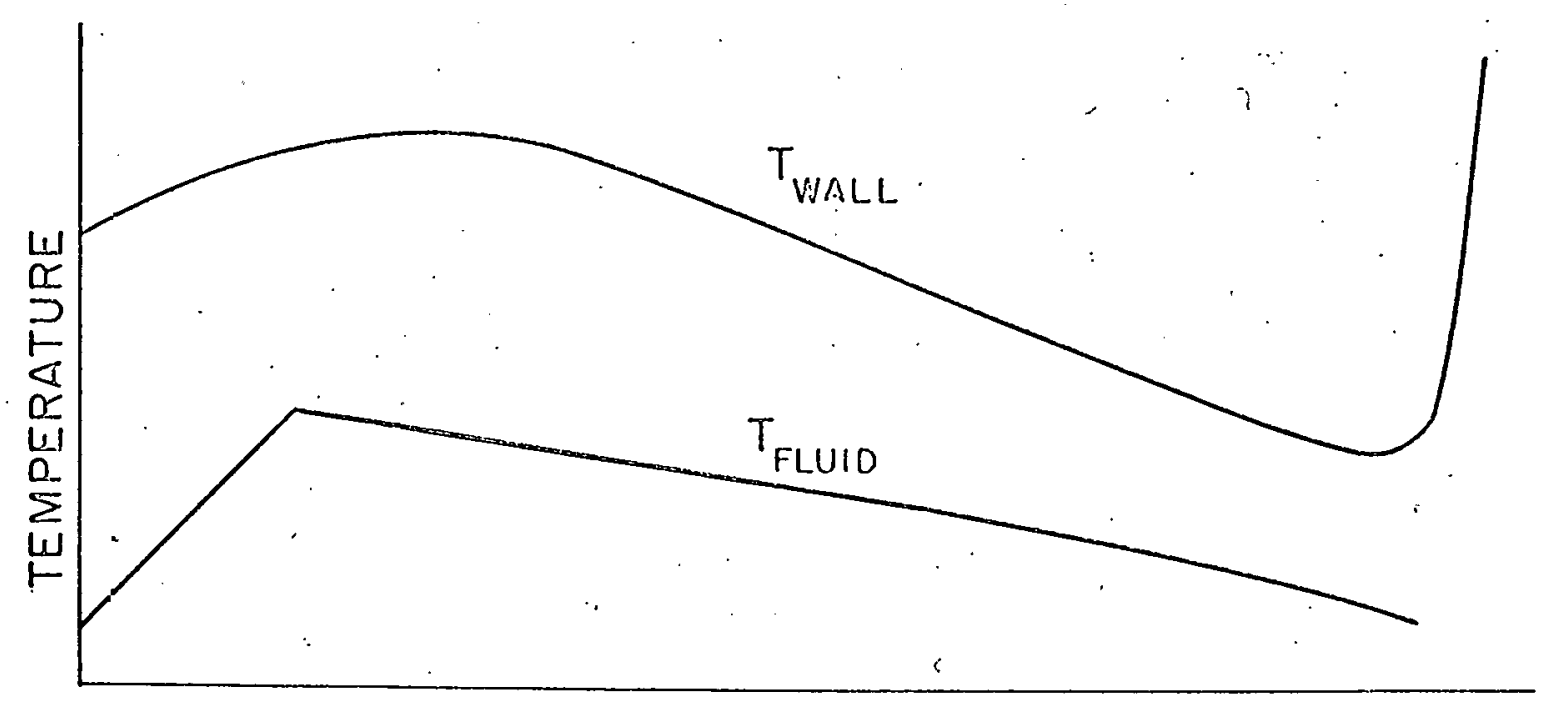

DISTANCE ALONG BOILER $\longrightarrow$

(B) LONGITUDINAL TEMPERATURE PROFILES 


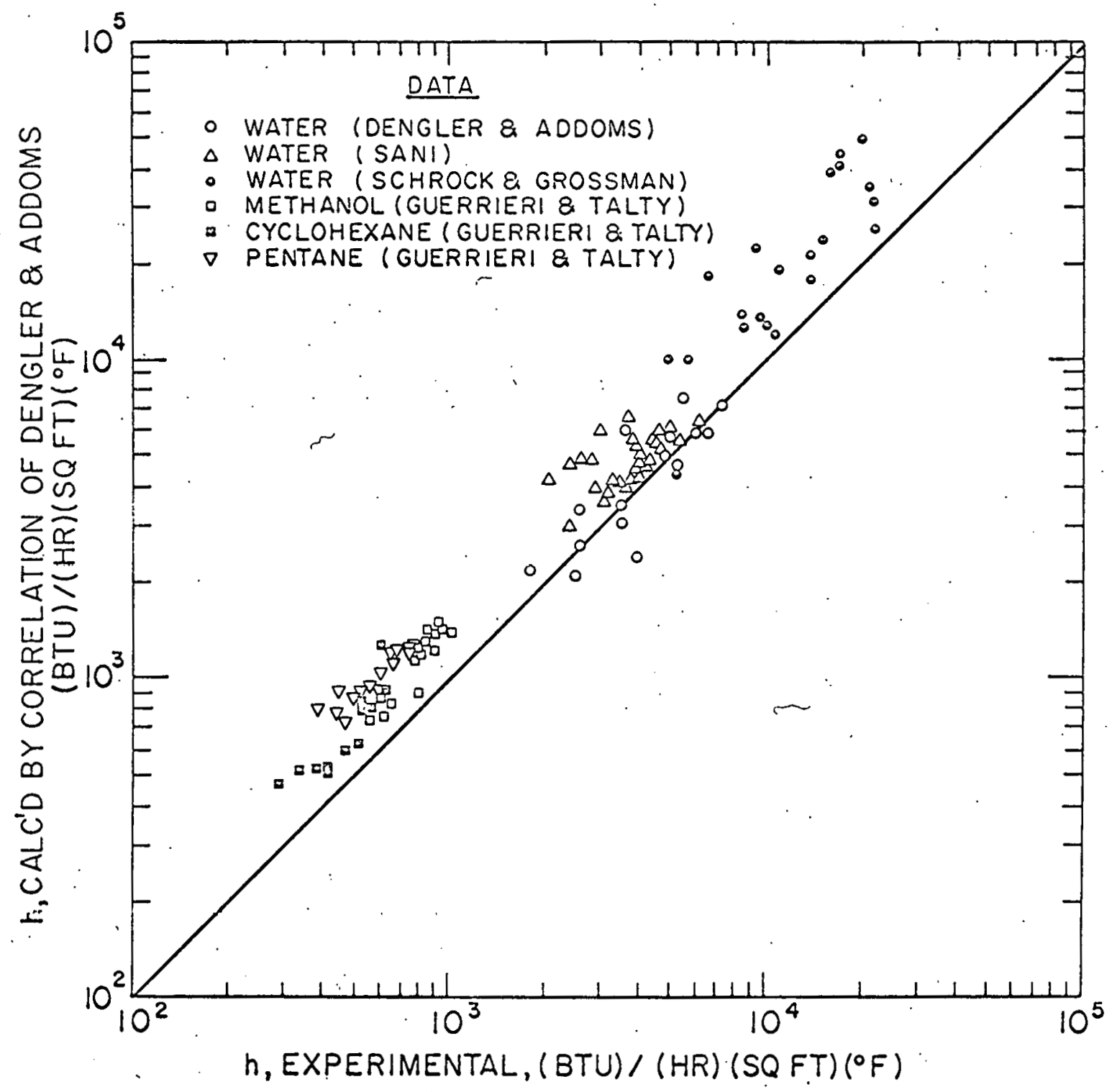

Fig. 2 


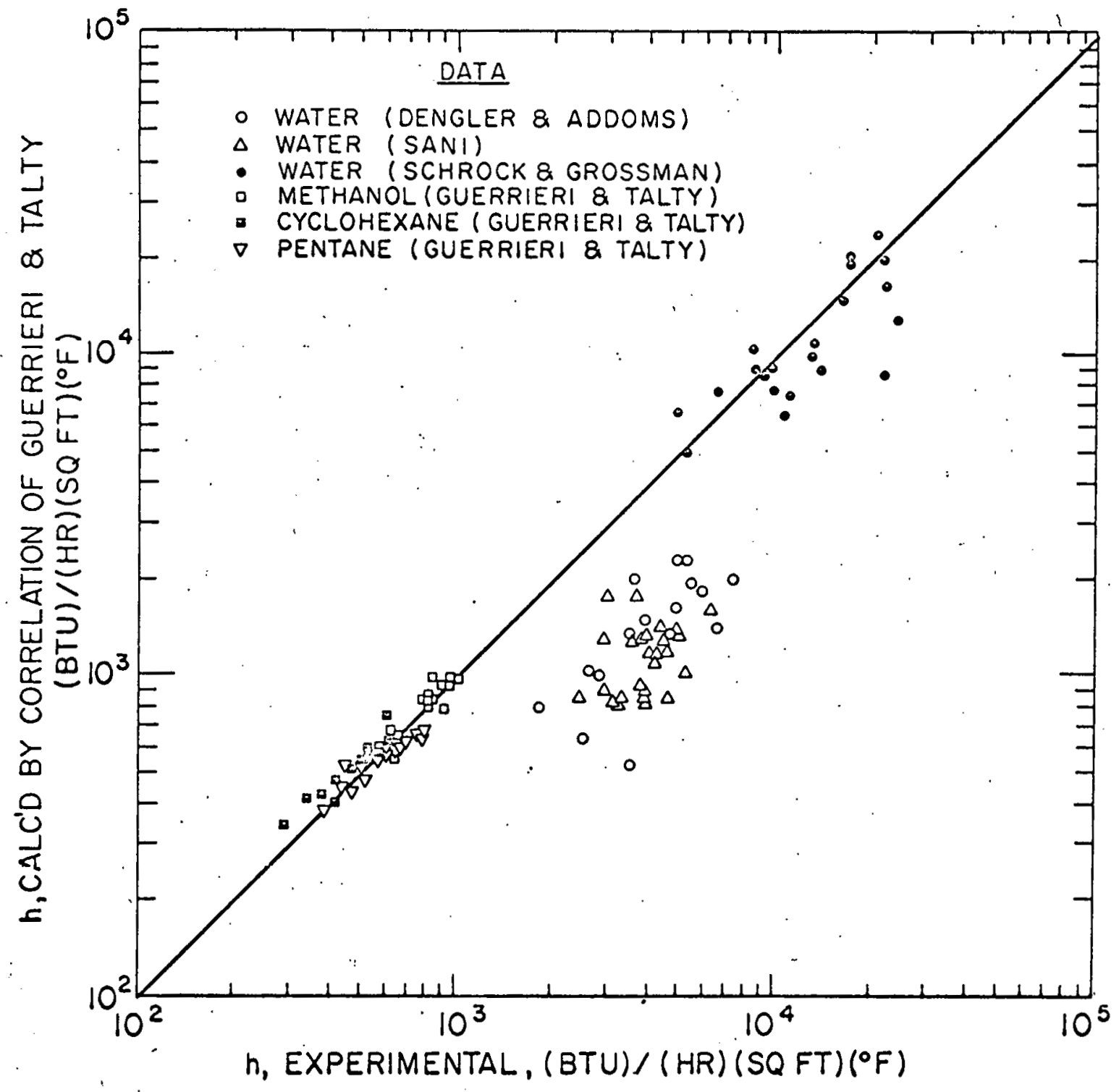

25 


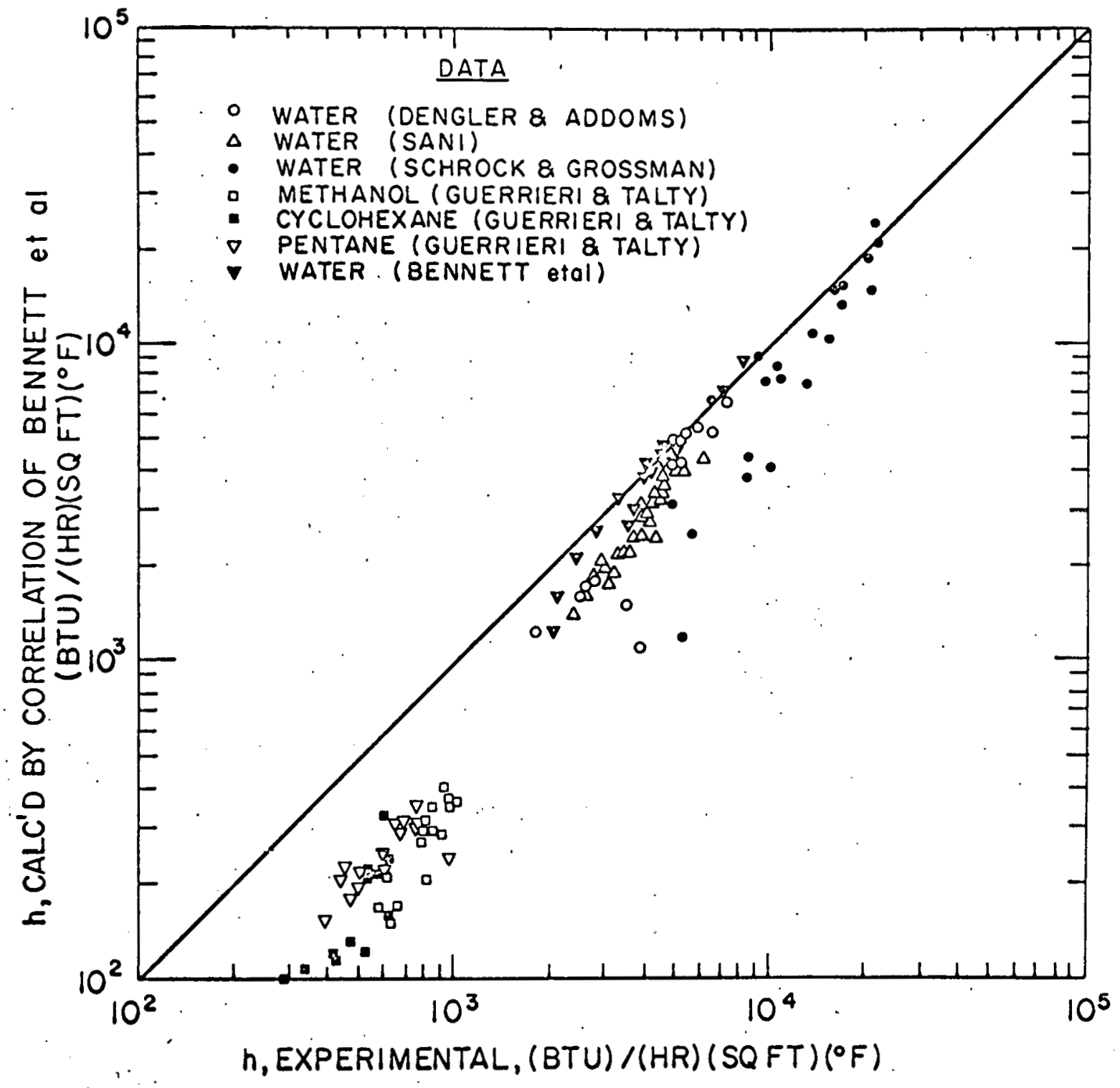

Fig. 4 


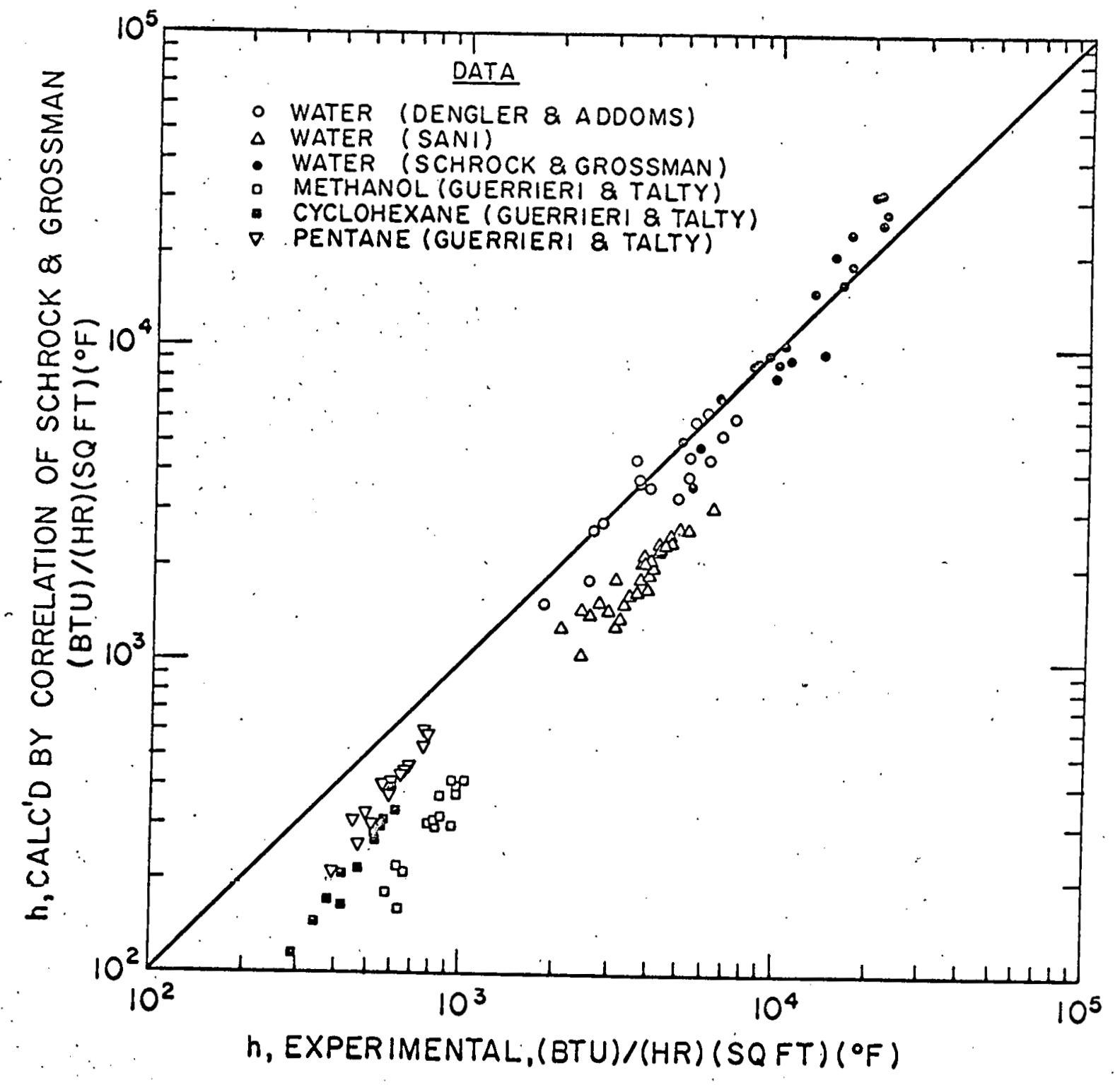

Fig. 5

J. c. Chen $\quad \& 7$ 


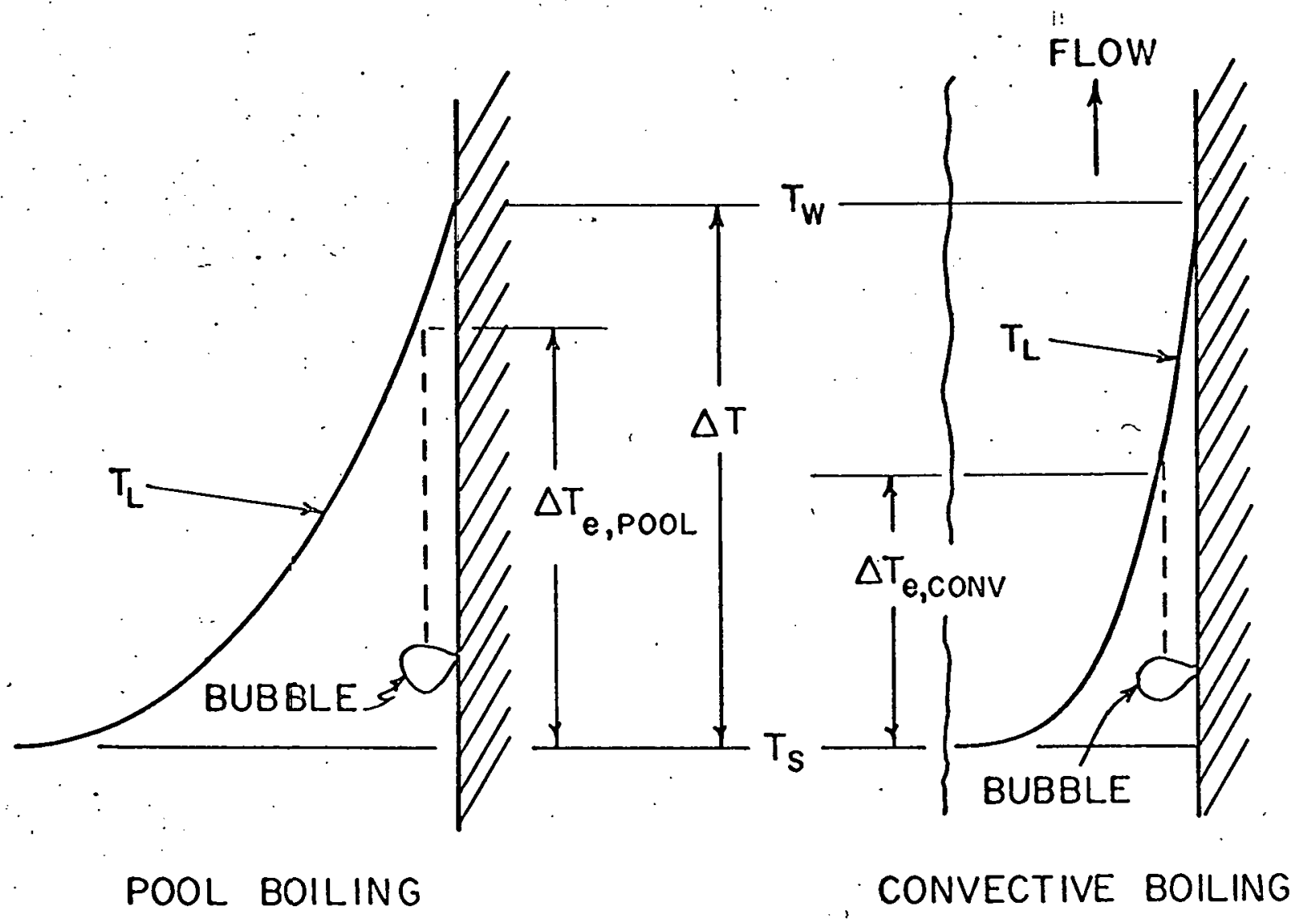

Fig. 6

J. C. Chen 


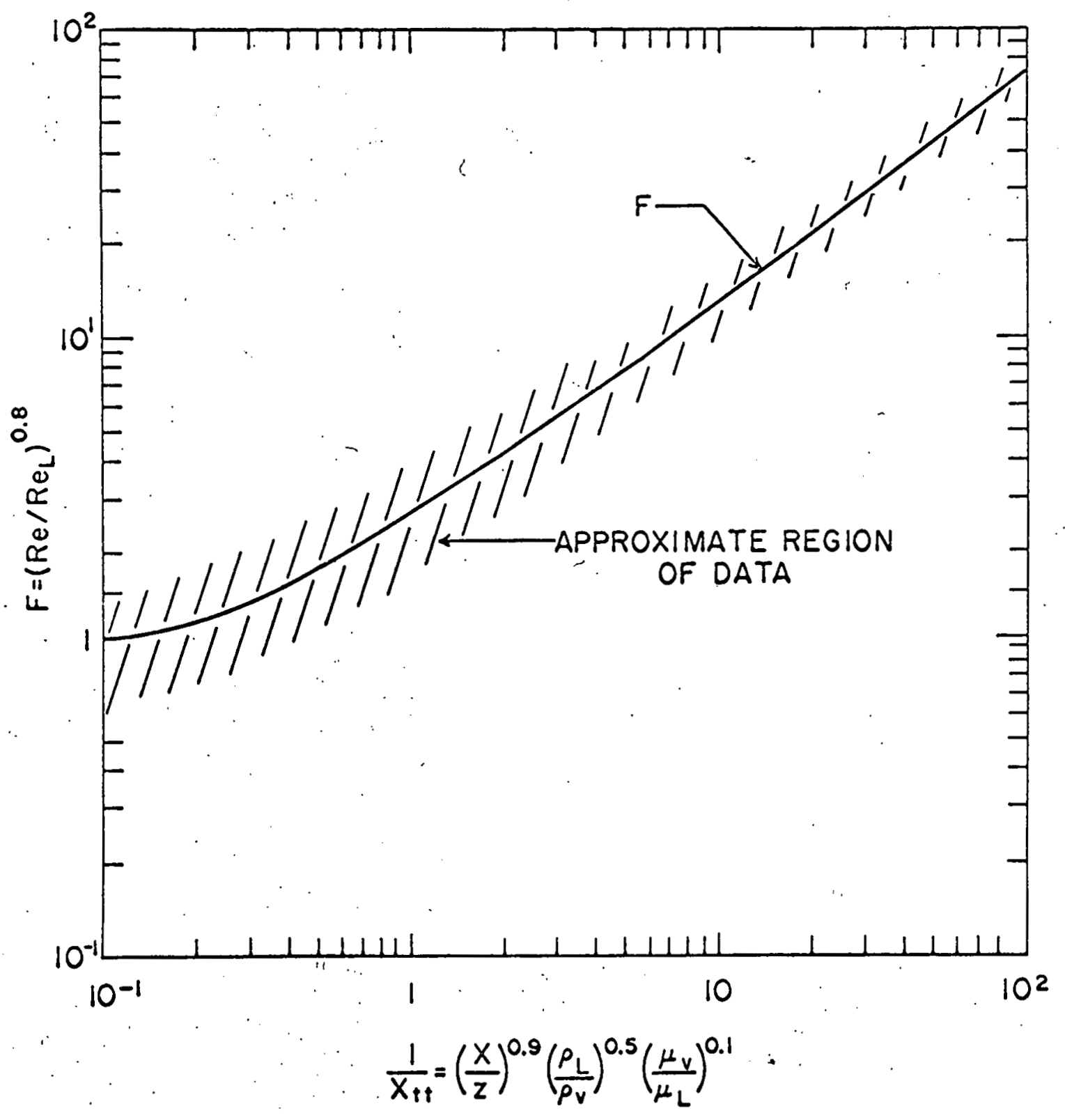

29

Fig. 7 


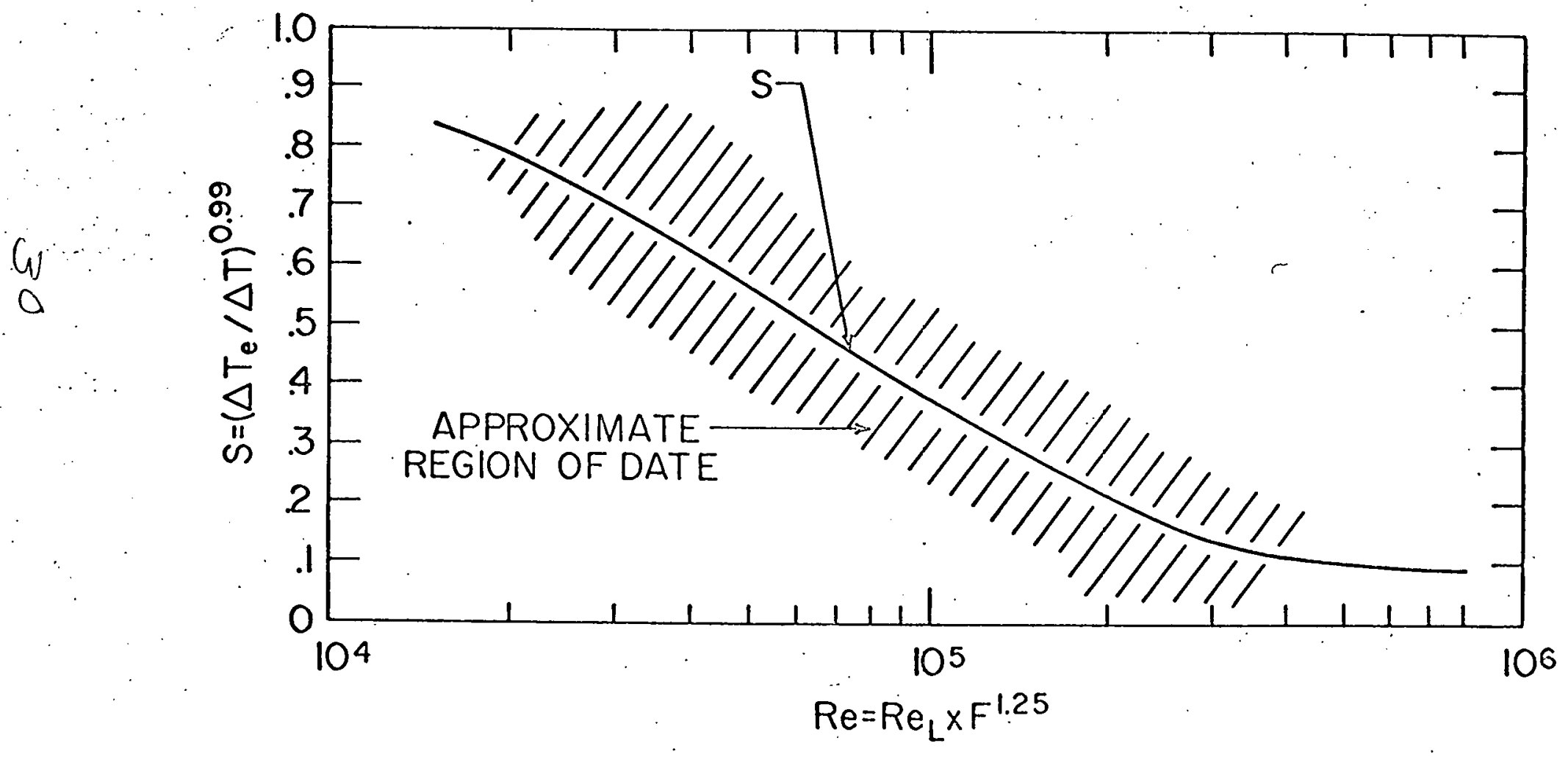

Fig. 8

J. C. Chen 


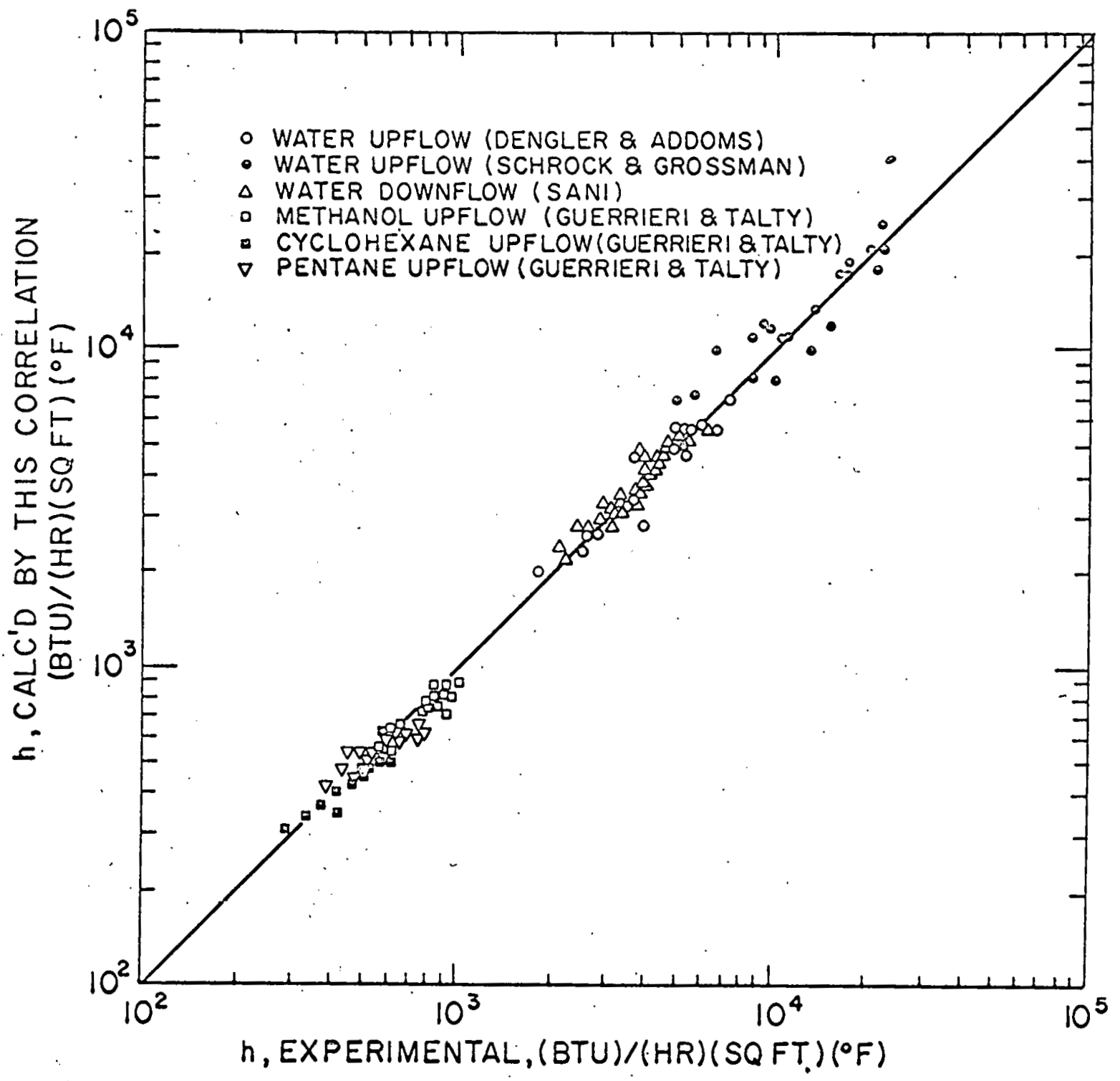




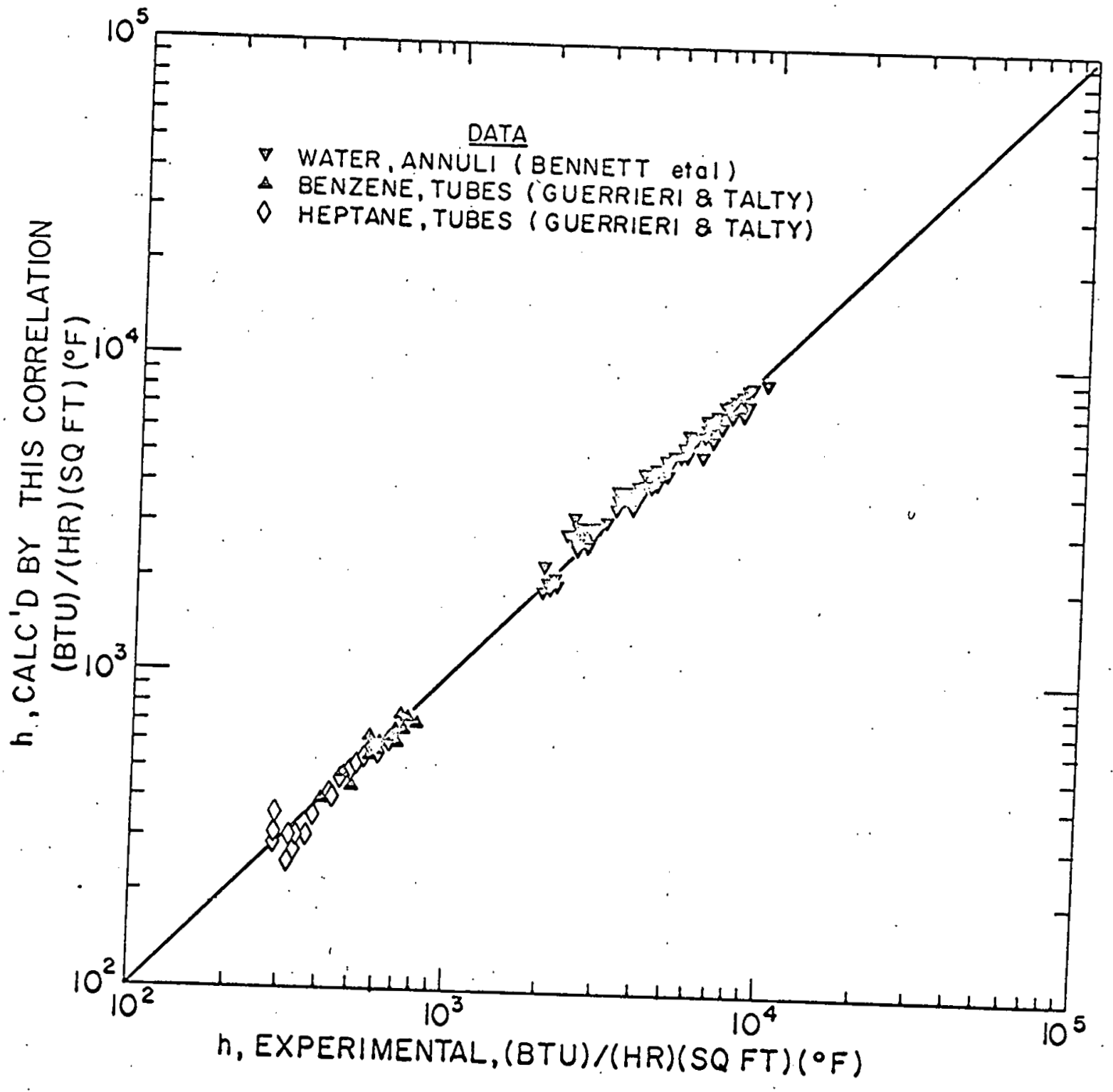

32

ig. 10

C. Chen 


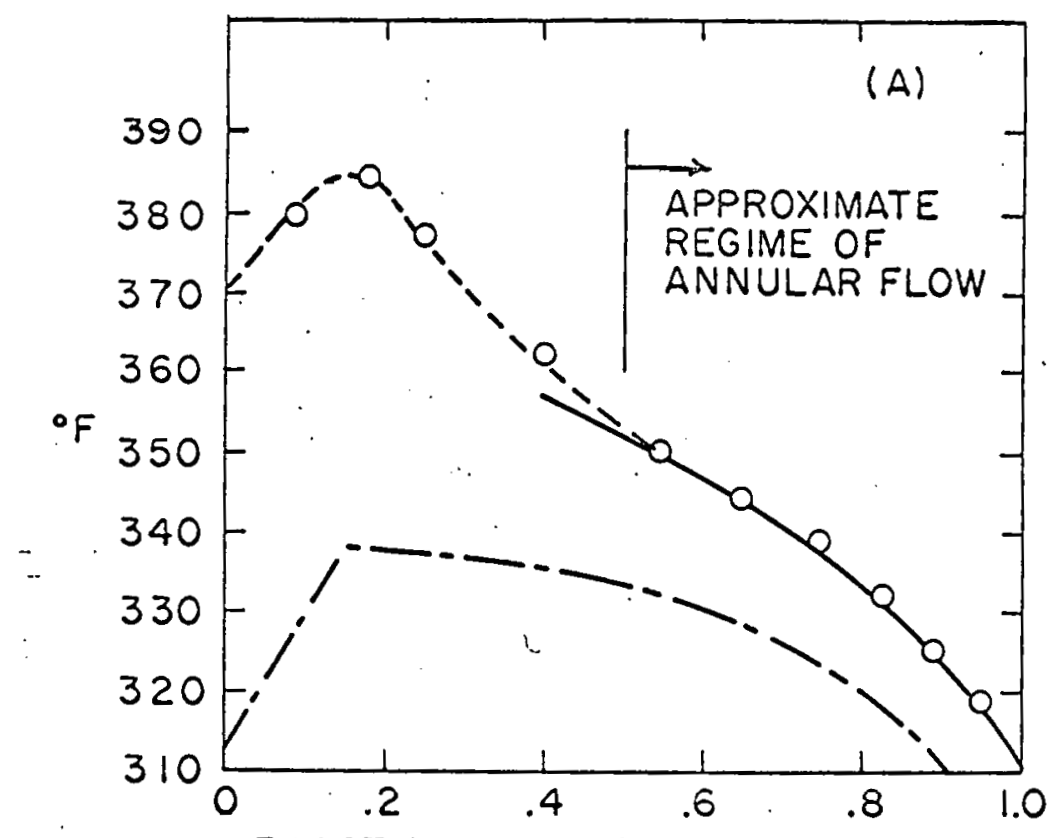

FRACTION OF DISTANCE ALONG BOILER

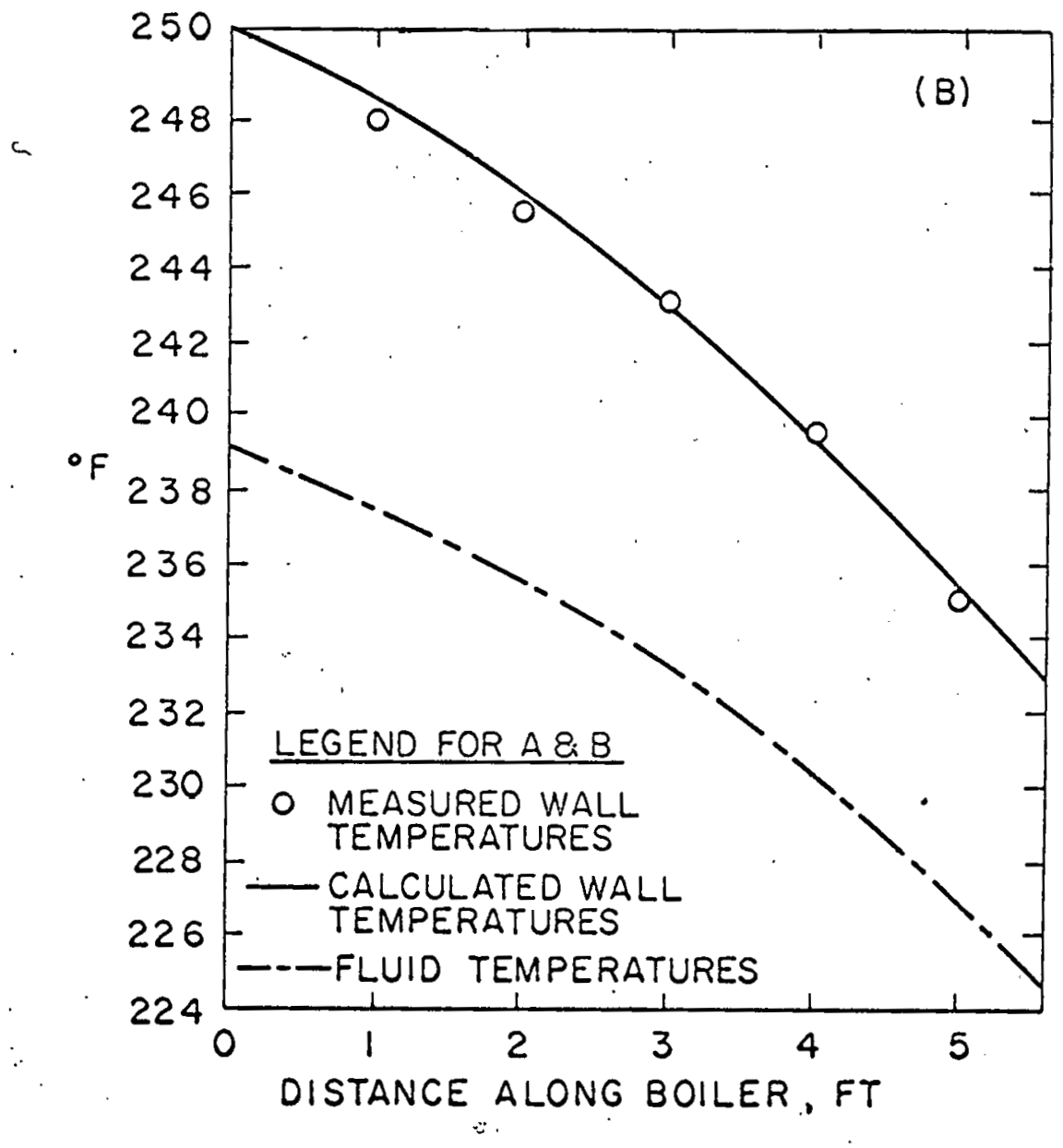

Fig. II 


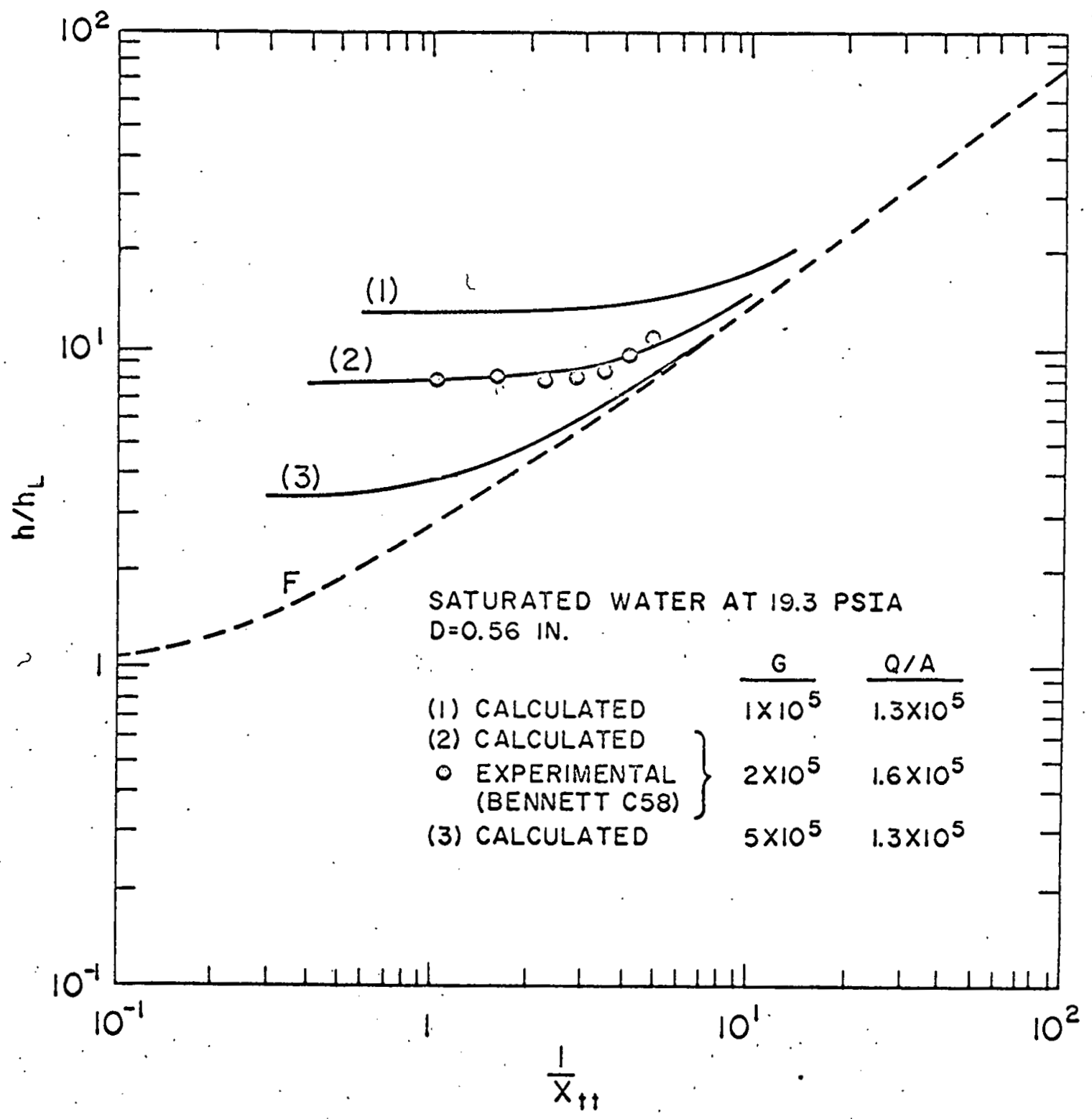

34

Fig. 12

J. c. Chen 